\section{Seven-up, the D rosophila homolog of the COUP-TF orphan receptors, controls cell proliferation in the insect kidney}

\section{Birgit Kerber, Sonja Fellert, and Michael Hoch ${ }^{1}$}

Max-Planck-Institut für Biophysikalische Chemie, Abteilung M olekulare Entwicklungsbiologie, 37077 Göttingen, Germany

Morphogenesis of the insect kidney, the Malpighian tubules, is controlled in D rosophila by a single large cell, the tip cell. It has been postulated that this cell sends out a mitogenic signal that induces the division of neighboring cells. The signal and the molecules that receive it have remained elusive. We show that the COUP-TF-related nuclear orphan receptor Seven-up is a key component that becomes induced in response to mitogenic EGF receptor signaling activity emanating from the tip cell. Seven-up in tum is capable of regulating the transcription of cell cycle regulators.

Received January 19, 1998; revised version accepted A pril 8, 1998.

Pattern formation and morphogenesis are interconnected processes in development (Gurdon 1992). Whereas great progress has been made to elucidate the genetic and molecular interactions that govern patternforming events ( $N$ üsslein-Volhard 1991; Greenwald and Rubin 1992; Lawrence and Struhl 1996), much less is known on how developmental cues direct morphogenesis during the formation of tissues and organs in animals (Edgar and Lehner 1996; Follette and O'Farrell 1997). The Drosophila Malpighian tubules (MTs), which form a simple excretory epithelium comparable in function with kidneys in vertebrates (Wessing and Eichel berg 1978; Skaer 1993), offer a model system to study the interplay between patterning and cell proliferation, which is one important aspect of morphogenesis.

MTs function as the insect kidney both in the larva and the adult (Wessing and Eichel berg 1978). They consist of two pairs of blind ending tubes that are composed of a single cell-layered epithelium with a tightly controlled number of cells (Janning et al . 1986; Skaer 1993). The tubules float in the hemolymph from where they take up nitrogenous waste that is excreted as uric acid. During embryogenesis, MTs evert as four protuberances from the hindgut primordium, the proctodeum (Fig. 1A; Skaer 1993). The everting tubules grow by cell proliferation, which takes place in a few cells along the tubules

[Key Words: Drosophila; Malpighian tubules; cell proliferation; EGF receptor; seven-up/string]

${ }^{1}$ Corresponding author.

E-MAIL mhoch@gwdgde; FAX 49-551-2011755. and extensively in a distal proliferation domain in their tip region. Cell ablation experiments and studies on the pattern of cell division have shown that a single large cell at the distal end of each tubule, termed the tip cell, is decisive for controlling the proliferation of its neighboring cells (Skaer 1989). The tip cell that differentiates into a cell with neuronal characteristics during later stages of development (Fig. 1B) arises by division of a tip mother cell that is selected in the tubule primordium by lateral inhibition involving the $\mathrm{N}$ otch signaling pathway and the transcription factor Krüppel $(\mathrm{Kr}$; Hoch et al. 1994) (Fig. 1C-F). It has been suggested that the tip cell sends a mitogenic signal to adjacent cells in the distal proliferation zone (Skaer 1989). It has remained elusive, however, what the signal is or what its target molecules in the signal-receiving cells could be and how cell proliferation during MT morphogenesis is regulated.

\section{Results and Discussion}

The orphan receptor Seven-up controls cell proliferation during tubule devel opment

In searching for regulators of cell proliferation, we identified the seven-up (svp) gene to be important for MT growth. svp encodes a homol og of the human transcription factor COUP-TF (M lodzik et al. 1990; Power et al. 1991) and belongs to the steroid/thyroid hormone receptor superfamily (Thummel 1995). Svp has been shown previously to be involved in photoreceptor cell fate determination in the eye (Hiromi et al. 1993; Begemann et al. 1995; Kramer et al. 1995). Two types of transcripts have been characterized at the svp locus (Mlodzik, et al. 1990): svp type I encodes a protein with both a DNAbinding domain and a ligand binding domain (LBD); and svp type II diverges from type I in the middle of the LBD. Both isoforms are highly conserved in evolution; homologs that are involved in neurogenesis and organogenesi s have been identified in vertebrates and invertebrates (Tsai and Tsai 1997).

During MT development, both isoforms of svp are expressed in the same pattern. Their expressi on can first be detected in embryonic stage 10 (Campos-Ortega and Hartenstein 1997) on one side of the outgrowing tubules and, later, during the eversion, in a group of about six to eight cells in the tip region (Fig. 1G-I). Analysis of the MTs of amorphic svp mutants reveal ed a reduction of the tubule cell number compared to wild type (T able 1; Fig. IM). Anti-Kr antibody stainings reveal that the MT precursor cells are specified normally in svp mutants indicating that the cause for the defect is not attributable to cell death that might lead to a size reduction of the tubule primordium (Fig. 1J). Furthermore, tip cell determination occurs normally in the mutants (Fig. $1 \mathrm{~K}, \mathrm{~L}$ ). Rather, pulse labeling with BrdU, suggests that the re duction of the cell number results from a failure of proper cell divisions. In wild-type embryos, BrdU incorporation occurs asymmetrically on one side of each tubule in proliferating cells. When MT eversion begins in 

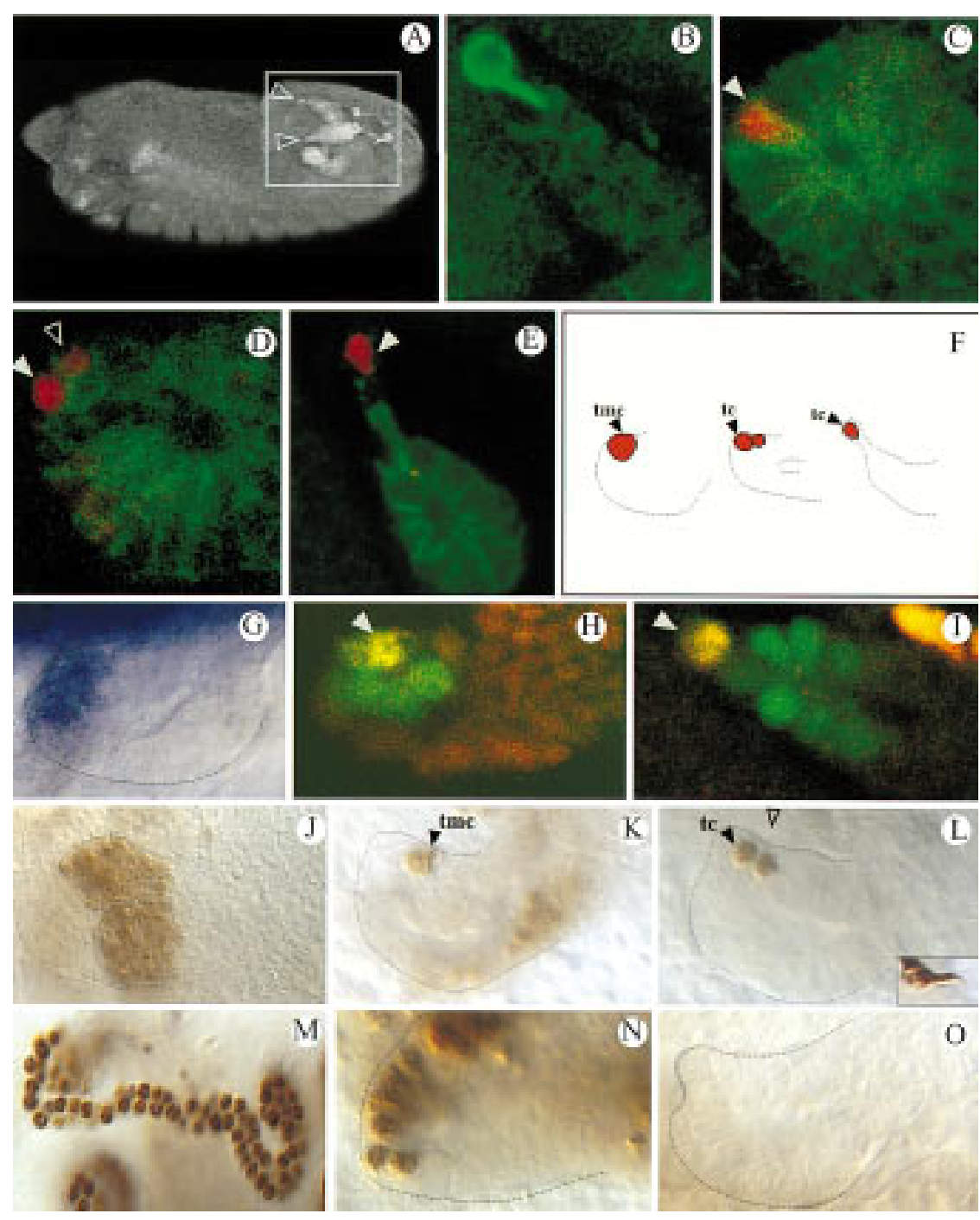

Figure 1. svp is required for MT growth. (A) Dorsolateral view of a stage 13 embryo visualizing two of the four everting tubules (inset, arrowheads) by mAb Fascll labels tubule membranes. (B) mAb 22C10, mAb Fascll double staining (both green) of a stage 16 tubule; 22C10 expression marks the neural tip cell. (C-E) Anti-Kr (red), mAb Fascll (green) double stainings highlighting the tip mother cell in stage 10 (C, arrowhead), the two daughter cells shortly thereafter ( $D$, arrowheads) and the tip cell in stage $14(E$, arrowhead). (F) Scheme of tip cell allocation. (G-I) svp expression monitored by in situ hybridization (G; stage 11 tubule) or via a svp lacZ line ( $\mathrm{H}, \mathrm{l}$; late stage 11$)$ showing the same expression pattern. Anti- $\beta$-gal (green), anti-Kr (red) double stainings. Yellow shows coexpression of svp and $\mathrm{Kr}$ in the tip mother cell $(\mathrm{H}$; arrowhead) and the tip cell (I; arrowhead). (J-M,O) svp mutant embryos, (N) wild type. (J-L) Anti-Kr staining. The primordium $(\mathrm{J})$, tip cell allocation $(K, \mathrm{~L})$, and tip cell differentiation (inset in $\mathrm{L}, \mathrm{mAb}$ $22 \mathrm{C} 10$ stains) are normal. (M) Anti-Cut staining reveals a reduced tubule cell number in svp mutants (T able 1). ( $\mathrm{N}, \mathrm{O})$ BrDU incorporation studies of stage 11 embryos. (tmc) Tip mother cell; (tc) tip cell.

stage 10 , the dividing cells in the distal tip region continue to incorporate BrdU extensively (Fig. $1 \mathrm{~N}$ ) until the end of stage 13 when division stops (Janning, et al. 1986; Skaer 1989). Subsequently, intense BrdU incorporation occurs in all of the tubule cells during endomitotic cycles that take place in a proximal to distal direction in the tubules. In svp mutants we found relatively normal $\mathrm{BrDU}$ incorporation during the initial cell divisions, but
$\mathrm{O}$

subsequently it was strongly reduced indicating a failure of DN A replication (Fig. 10). In the later occurring endomitotic cycles, the BrdU pattern was normal again (not shown), indicating that a specific block of $S$ phases occurs in dividing cells, but not during the endomitotic cycles. These results suggest that svp, which is expressed in the proliferation domains marked by BrdU, might be an integral component of the regulatory network that regulates division in the cells that receive the mitogenic signal from the tip cell.

rhomboid and Star activities in the mitogenic tip cell

To identify the nature of the mitogenic tip cell signal we screened for genes specifically active in the tip cells. We found that the genes rhomboid (rho) and Star (S), which encode transmembrane proteins (Bier et al. 1990; Kolodkin et al. 1994) shown previously to be involved in epidermal growth factor receptor (EGFR) signaling (Freeman 1997; Schweitzer and Shilo 1997), are expressed in the tip cells and that both are required for MT growth. When the tubules start to evert, rho and $\mathrm{S}$ are expressed in the tip mother cell (Fig. 2A,C,E); subsequently rho is strongly expressed in the tip cell (Fig. 2B,E) and $S$ in the tip cell and its former sister cell (Fig. $2 D, E)$. An analysis of the MTs in the corresponding amorphic mutants reveal ed a strong decrease of cells in rho mutants and a weaker decrease in $\mathrm{S}$ mutants (Table 1 ). In a rho; $S$ double mutant, the tubules are barely detectable (Table 1 ) indicating that rho and $S$ activities are essential, al beit redundant, components controlling MT growth. The tubule phenotype of rho;S double mutants is very similar to the one of EGFR mutants, which also show a drastic decrease of the tubule cell number (Baumann and Skaer 1993; Table 1). As in svp mutants, the allocation and the differentiation of the tip cells are normal in the receptor mutants (not shown) indicating that receptor activity is not required for tip cell determination and differentiation. The reduction of the tubule cell number in EGFR mutants is not due to cell death as indicated by acridine orange and TUNEL experiments (this paper; see also Clifford and Schüpbach 1992; Baumann and Skaer 1993) but, rather, to a failure of proper cell divisions. N o BrdU incorpora- 
Table 1. Tubule cell number in various mutants

\begin{tabular}{|c|c|c|}
\hline \multirow[b]{2}{*}{ Mutant allele } & \multicolumn{2}{|c|}{ Tubule cell number (S.D.) } \\
\hline & anterior & posterior \\
\hline Wild type & $140 \quad( \pm 4)$ & $106.7( \pm 6.1)$ \\
\hline $\operatorname{svp}^{\mathrm{e} 22}$ & $96.3( \pm 5.2)$ & $84.4( \pm 5.8)$ \\
\hline$v^{4}$ & $89.3( \pm 4.7)$ & $58 \quad( \pm 4.3)$ \\
\hline $\mathrm{S}^{1 \mathrm{IN} 23}$ & $104.2( \pm 13.4)$ & $65.7( \pm 14.7)$ \\
\hline $\mathrm{S}^{\prime \prime I N 23} ; \mathrm{ve}^{4}$ & $24.3( \pm 2.6)$ & N.D. \\
\hline $\mathrm{flb}^{1 \mathrm{~K} 35}$ & $26 \quad( \pm 6.1)$ & $19.8( \pm 1.3)$ \\
\hline pnt $^{\Delta 88}$ & $99 \quad( \pm 8.6)$ & $70 \quad( \pm 10.3)$ \\
\hline spi ${ }^{11 T 25}$ & $23.3( \pm 1)^{*}$ & \\
\hline G455.2 ×UASsvplI & $158 \quad( \pm 3)$ & N.D. \\
\hline
\end{tabular}

$\mathrm{N}$ umber of tubule cells based on anti-Cut antibody stainings that allow the counting of tubule cells. N umbers are given for anterior and posterior tubules separately. $\mathrm{flb}^{1 \mathrm{~K} 35}$ is a null mutant for the EGFR, ve is a null allele for rho, spi ${ }^{11 T 25}$ is a null mutant for the EGFR ligand Spitz. (*) Average number for a single tubule; $(n=4)$ for $\mathrm{S}^{\text {IIN23; }}$ ve $\mathrm{e}^{4}$ double mutants; $(n>6)$ for the rest; (N.D.) not determined.

tion occurs in EGFR mutants in the outbudding tubules at the time when cells divide in wild-type embryos (Fig. 2G). However, BrdU incorporation occurs again much later during the endomitotic cycles (Fig. $2 \mathrm{H}$ ), indicating that in EGFR muants, a specific defect in DNA replication exists in cells that would normally divide.

In vitro and in vivo studies on the mechanisms of EGFR signaling during cell determination in the embryonic CNS and the eye (Freeman 1997; Schweitzer and Shilo 1997) have suggested that Rho and S process a membrane-bound form of the activating ligand of the receptor, the TGF $\alpha$-like Spi protein, to generate the secreted form of Spi (sSpi). sSpi is then proposed to diffuse to neighboring cells, bind to the receptor, and activate target genes via the Ras/R af signal ing cassette; these include the primary target gene pointed ${ }^{\mathrm{Pl}}\left(\mathrm{pnt}^{\mathrm{P} 1}\right)$, encoding an ETS domain transcription factor (Klämbt 1993), and the secondary target gene argos (aos), encoding a negatively acting ligand of the receptor (Freeman et al. 1992; Gabay et al. 1996). These downstream components of the pathway are al so active during tubule development. pnt ${ }^{P 1}$ and aos are expressed during stage 10 in six to eight cells on one side of the MTs overlapping the rho and S expression domains and later, weakly in several cells in the tip region (Fig. 2F). In amorphic aos mutants we observe a slightly larger number of tubule cells, whereas amorphic pnt mutants show a decrease of tubule cells (Table 1). These results indicate that for controlling cell proliferation and cell determination, the same key components of the EGFR cascade are required.

\section{svp is a downstream target gene of EGFR signaling} activity

Our findings suggest that the EGFR pathway provides the mitogenic tip cell signal that activates svp expression and regulates cell division. To test this hypothesis, we analyzed svp expression in EGFR mutants and performed ectopic expression studies with various members of the pathway using the UAS-Gal4 system (Brand and
Perrimon 1993). svp is absent in mutants for the EGFR (Fig. 3A ,B). It is still expressed, however, in amorphic pnt mutants (not shown), suggesting that Svp is a transcriptional regulator that is likely to be activated in parallel to the primary transcription factor $\mathrm{Pnt}^{\mathrm{P} 1}$ in the signaling cascade. If sSpi activity is provided ectopically in all of the tubule cells using a ubiquitously expressing MTGal4 driver and a U AS-sSpi effector gene, the svp expression domain becomes dramatically expanded and an increase of the tubule cell number is observed (Fig. 3C). Similar, although slightly weaker effects on svp transcription and the number of tubule cells could be observed upon ubiquitous expression of other components of the EGFR pathway, like Rho, activated Ras, or Raf (not shown). Conversely, when a dominant-negative Ras allele was ectopically expressed in all of the tubule cells,
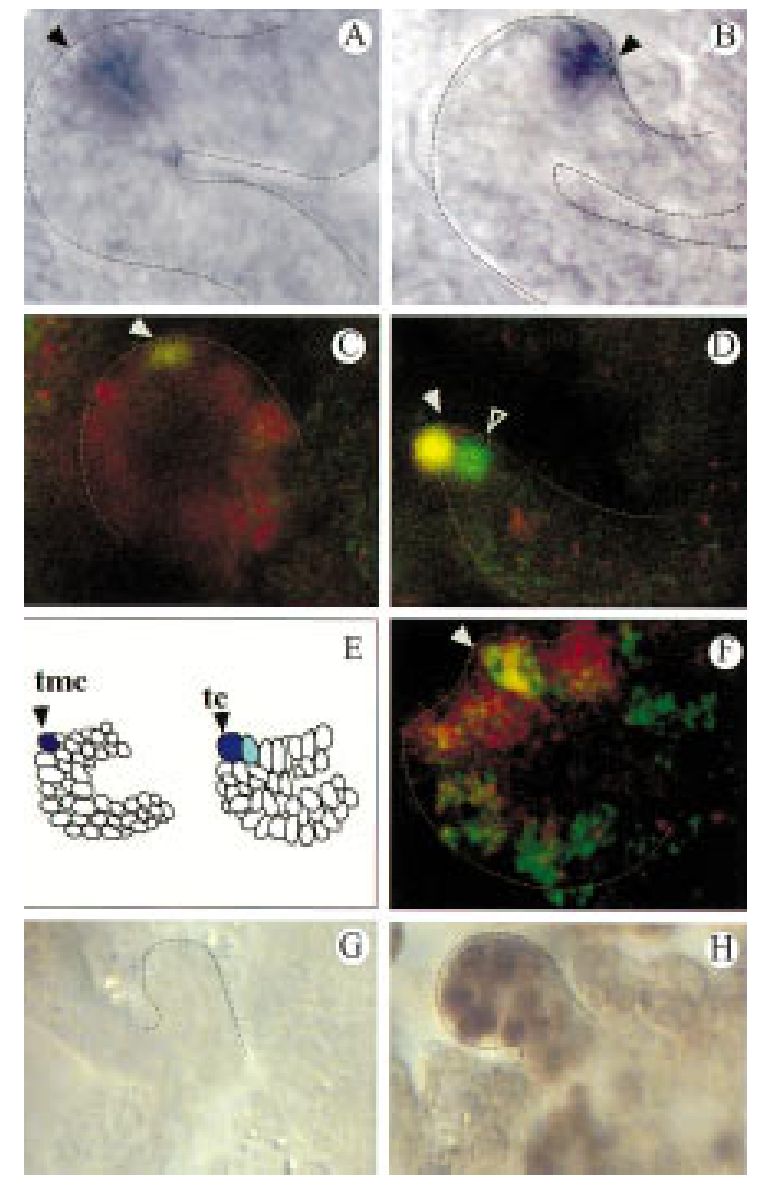

Figure 2. Localized rho and $S$ activity in the tip cells of the tubules. $(A, B)$ rho expression in the tip mother cell ( $A$, arrowhead) and the tip cell (B, arrowhead) as revealed by in situ hybridization. (C,D) S lacZ expression; double staining of anti- $\beta$ gal (green) and anti-Kr (red) revealing $S$ expression in the tip mother cell (C, arrowhead), the tip cell ( $D$, arrowhead), and its sibling cell ( $D$, open arrowhead). (E) Summary of the rho (blue) and $S$ (light blue) expression patterns in the everting tubules. (F) pnt-lacZ expression; double staining of anti- $\beta$-gal (red) and anti$\mathrm{Kr}$ (green) revealing pnt expression in the tip mother cell (arrowhead) and its neighboring cells. (G,H) BrdU incorporation studies in EGFR mutants (fl| ${ }^{1 \mathrm{~K} 35}$; stage 12; G) and (stage 15; H). 


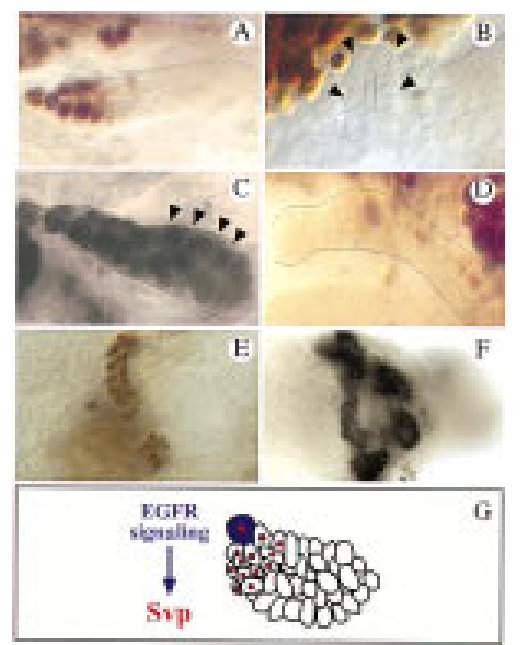

Figure 3. svp expression is dependent on EGFR signaling. (AD) svp lacZ expression shown by anti- $\beta$-gal antibody stainings (the same results were obtained monitoring svp expression by in situ hybridization). (A) svp expression in the tip region of a wild-type tubule (stage 15). (B) svp lacZ expression is abolished in mutants of the EGFR ( $\mathrm{Flb}^{1 \mathrm{~K} 35}$ ). (C) U pon ectopic sSpi expression the svp domain is largely expanded (arrowheads point to cells that ectopically express svp; cf. A) and the cell number increases. (D) Ectopic expression of the dominant-negative Dras1 $^{\mathrm{N} 17}$ allele using the XB2-3-Gal4, reduces svp expression (cf. A). (E,F) Anti-Cut stainings marking all of the tubule cells. (E) Reduced tubule cell number in $\mathrm{fl}^{1 \mathrm{~K} 35}$ mutants. (F) Ectopic svp expression of rescues the tubules of $\mathrm{fl}^{1 \mathrm{~K} 35}$ mutants. Approximately three times more cells were obtained compared to the mutant condition. (G) Summary of the results. Svp (red nuclei) is activated by EGFR signaling, which emanates from the tip cell (blue) and controls cell division.

svp transcription became strongly reduced (Fig. 3D). Furthermore, ectopic expression of svp in an EGFR mutant background restored the tubule cell number to a considerable extent (Fig. 3E,F). These results provide strong evidence that svp is a downstream target gene of EGFR signaling in the tubules (Fig. 3G).

svp is both necessary and sufficient to induce cell divisions by regulating the activity of cell cycle genes

If Svp is expressed ectopically in wild-type MTs, an increased number of tubule cells is obtained (Table 1). BrdU incorporation studies indicated that this increased cell number results from extra cell divisions (Fig. 4A-D), indicating that svp is both necessary and sufficient to induce cell prol iferation in the MTs. To further elucidate how the EGFR pathway and svp control cell proliferation, we analyzed whether these developmental regulators have an impact on components of the cell cycle machinery during MT growth. We examined the expression of two genes that are limiting key components of the cell cycle during the period when the MT cells proliferate: string (stg), which encodes a $\mathrm{Cdc} 25$ phosphatase involved in the regulation of the $\mathrm{G}_{2} / \mathrm{M}$ transition (Edgar and O'Farrell 1990) and cyclin E (cycE), which regulates the $\mathrm{G}_{1} / \mathrm{S}$ transition (Richardson et al. 1993; Knoblich et al. 1994). In situ hybridization reveal s that both genes are expressed asymmetrically in the everting tubules and subsequently in the distal proliferation zone (Fig. 4E,G). These expression domains match the svp expression domain. With the onset of the endomitotic cycles, a second phase of cycE expression occurs from proximal to distal in the tubules (not shown). In EGFR mutants, the transcriptional activation of stg and cycE, which occurs in the tubule proliferation domains in wild type, cannot be detected (Fig. $4 \mathrm{H}, \mathrm{I})$. This correl ates with a strong reduction of BrdU incorporation and the dramatic reduction of the tubule cell number in EGFR mutants (Fig. 2G; Table 1). During the subsequent endomitotic cycles, expression of cycE is not affected (not shown), indicating a specific function of EGFR signaling in activating early cycE expression. In svp mutants, the expression of stg and cycE is reduced (most likely reflecting that Svp is only one of the regulators that transmits the mitogenic EGFR signal; see below); however, in MTs in which svp is ectopically expressed, stg becomes transcriptionally misexpressed in the cells that undergo extra cell divisions (Fig. 4, cf. F to B and E). We obtained similar, although weaker misexpression with CycE (not shown). Extra cell divisions can, however, only be obtained early during $\mathrm{MT}$ outgrowth suggesting that other regulators

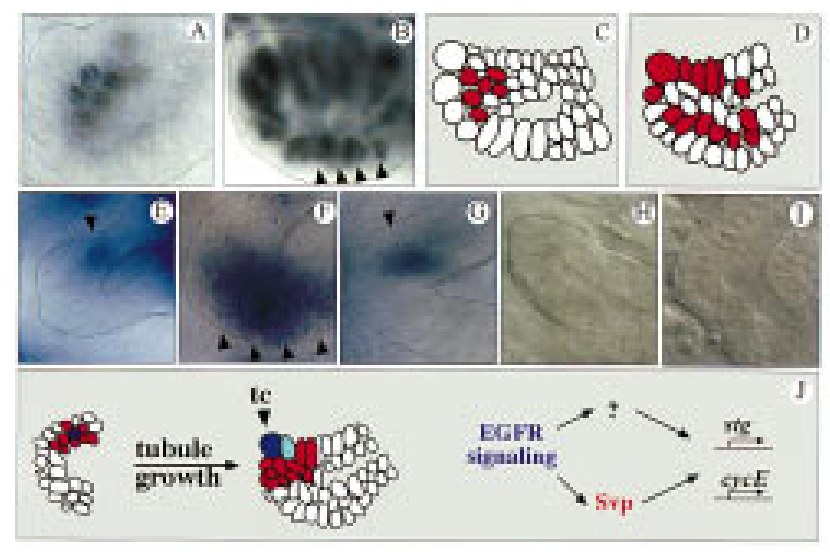

Figure 4. EGFR signaling and Svp control cell cycle gene expression. BrDU incorporation in stage 10 wild-type (A) and G455.2-Gal4/UAS-Svp II tubules (mediating SvplI expression in all tubule cells) (B). Cell proliferation does not occur on one side of the outgrowing tubules as in wild type (A) but throughout the everting tubules (B, arrowheads). (C,D) Schematic representation of the BrdU incorporation studies in $A$ and $B$. Red marks cell division. (E-I) RNA in situ hybridization experiments of wild-type $(E-G)$ and $\left(f \mid b^{1 K 35}\right)$ mutant embryos $(H-I)$. (E) stg expression in proliferating tubule cells of wild-type embryos occurs on one side of the outgrowing tubule (arrowhead) in early stage 10. (F) U pon ectopic expression of Svp, stg becomes ectopically expressed in cells that undergo extra divisions (arrowheads, cf. E and B). In wild type, cycE is also expressed asymmetrically in the outgrowing tubules in stage 10 (G; arrowhead) and in the distal proliferation zone (not shown). Localized transcription of stg $(\mathrm{H}$; stage 11$)$ and cycE $(\mathrm{I}$; stage 10$)$ is absent in $\mathrm{flb}^{1 \mathrm{~K} 35}$ mutants. (J) M odel of how tip cell (blue) signaling might control tubule growth. Dividing cells are red; See text for details. 
limit cell proliferation during later stages of MT development.

\section{Concluding remarks}

The mitogenic property of EGFR signaling is known mainly from vertebrate studies. A deregulation of signaling activity can cause uncontrolled cell growth and proliferation, leading to the formation of various tumors and cancers (Schlessinger and Ullrich 1992). In Drosophila, EGFR signaling has been studied mainly in the context of cell determination, although there is al so compelling evidence for a role in mitogenesis. It has been shown that mutant EGFR clones in wing, haltere, and eye imaginal discs fail to prol iferate normally (Clifford and Schüpbach 1989; Xu and Rubin 1993) and, conversely, supernumerary mitoses appear in eye imaginal discs of Iarvae carrying a dominant gain-of-function allele of the EGFR (Zak and Shilo 1992). The underlying molecular mechanisms have, however, not yet been analyzed.

From our studies on tip cell-dependent control of cell proliferation in the MTs, we can deduce a model suggesting that EGFR signaling activity emanating from the tip cell induces svp expression in the signal-receiving cells (Fig. 4J). Svp, in turn, di rectly or indirectly activates the transcription of key components of the cell cycle thus promoting cell division during tubule outgrowth. Transcriptional regulation of cell cycle genes most likely occurs through distinct cis-acting el ements in their regulatory regi on. In the case of stg, such el ements have been identified (Edgar et al. 1994), and it was shown that stg transcription is activated via these elements by developmental regulators. It is possible that Svp might bind to such a MT element and directly or indi rectly regulatestg transcription. cycE might have two such elements, one of them regulating its expression in the proliferation domains (dependent on EGFR signaling; Fig. 4J) and the other during the endomitotic cycles in all of the tubule cells. Whether Svp, whose function has been characterized initially in the context of photoreceptor development in the eye (M lodzik et al. 1990) also plays a role for cell proliferation during eye imaginal disc development is not known.

Our results also indi cate that there must be other factors in addition to Svp that are dependent on EGF signaling and are involved in MT growth. This is apparent from the finding that the svp mutant phenotype is less severe than the one of EGFR mutants. Those predicted factors might include other steroid hormone receptors that interact with Svp as cofactors. Studies on ecdysone signaling pathways show that Svp can heterodimerize with subunits of the ecdysone receptor and regulate gene expression (Zel hof et al. 1995). Whether ecdysone-based signaling pathways also play a role in controlling cell proliferation in the MT is not known. Once cell proliferation is completed, the tubul e cells el ongate as a result of cell rearrangement and long thin tubes are generated with only two or three cells surrounding the lumen (Skaer 1993). We cannot exclude an additional role of EGFR signaling during later stages of MT development. This is consistent with recent results obtained with an antibody against the activated form of MAP kinase (dpERK), which visualizes the activated state of receptor tyrosine kinase (RTK) signaling pathways and shows a rather uniform dp-ERK pattern in all of the tubule cells (Gabay et al . 1997). As there is no apparent tubule elongation defect in svp mutants, other downstream factors must be involved in mediating this potential aspect of EGFR signaling. In summary, our data provide a framework for further analysis of the molecular mechanisms that underlie the control of cell proliferation by developmental regulators during MT morphogenesis.

\section{Materials and methods}

Drosophila stocks

Oregon- $\mathrm{R}, \mathrm{flb}^{1 \mathrm{~K} 35}, \mathrm{spi}^{11 \mathrm{~T} 25}, \mathrm{svp}^{\mathrm{e} 22}, \mathrm{ve}^{4}$, aos $^{\mathrm{wll} \Delta 7}, \mathrm{~S}^{11 \mathrm{~N} 23}, \mathrm{pnt}^{\Delta 88}, \mathrm{I}(3) 07825$ (pnt lacZ), I(3)07842 (svp lacZ), I(2)05671 (S lacZ) (Bloomington stock center; Karpen and Spradling 1992), UAS-sSpi, UAS-Rho (Gabay et al.

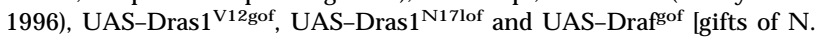
Perrimon (Harvard Medical School, Boston, MA)], XB2-3Gal4 (S. Stein, unpubl.), and G455.2Gal4 (a gift of U. Hinz, Universität Köln, Germany), both of which mediate rather ubiquitous expression in the tubule primordium and during tubule outgrowth. rho;S double mutants were generated according to genetic standard procedures.

Imunocytochemistry and in situ hybridization

Whole-mount RNA in situ hybridization was performed according to standard procedures. As templates, we used transcript-specific probes for svpl and svpl I (M lodzik et al. 1990), probes for Egfr and spi, rho, S (Gabay et al. 1996), and stg and cycE [gifts of C.F. Lehner (Edgar and Lehner 1996)]. Antibody staining of whole-mount embryos was carried out according to standard procedures. Antibodies were used: mAb 22C 10 and mAb Fascll (1:20; gifts of C. Goodman, University of California, Berkeley), anti- $\beta$-galactosidase (Cappel; 1:1000), anti-Kr (1:10; gift of U. Gaul, Rockefeller University, New York, NY), and mAb Cut (1:20; Hybridoma bank).

BrdU pulse labeling

BrdU (Sigma) labeling was performed, with modifications for embryos, essentially as described (Skaer 1989). Cell death was detected with acridine orange and with an adaptation of the TUNEL method (T. Imaoka, pers. comm.; Boehringer Mannheim).

Generation of UAS-Svp effector constructs

svpl and svpl I CDNAs were cloned into the pUAST vector (Brand and Perrimon 1993). Transgenic flies were generated by P-element-mediated transformation and stable lines were established. For the ectopic expression experiments, embryos were collected at $29^{\circ} \mathrm{C}$ and analyzed by RNA in situ hybridization or antibody stainings. In rescue experiments and in the ectopic expression assays, both UAS-Svp I and UAS-Svp II behaved the same.

\section{Acknowledgments}

We thank C. Klämbt, T. Hummel, T. Menne, B. Shilo, A. Michelson, M. M lodzik, C.F. Lehner, S. Stein, M. Gonzalez-Gaitan, and N. Perrimon for fly strains, probes and anti bodies; M.J. Pankratz for his many suggestions; G. Dowe, H. Jäckle, M.J. Pankratz, and the colleagues in the laboratory for comments on the manuscript; and W. Jahn for hel $p$ with the confocal microscope. B.K. was supported by a predoctoral fellowship of the Boehringer Ingelheim Fonds, and M.H. by the SFB271 and the Gerhard HessProgramm (Ho-1638/1-1).

The publication costs of this article were defrayed in part by payment of page charges. This article must therefore be hereby marked "advertisement" in accordance with 18 USC section 1734 solely to indicate this fact.

\section{References}

Baumann, P. and H. Skaer. 1993. The Drosophila EGFR homolog (DER) is required for Malpighian tubule development. Development (Suppl.) 65-75. 
Begemann, G., A.-M. Michon, L.v.d. Voorn, R. Wepf, and M. Mlodzik. 1995. The Drosophila orphan nuclear receptor Seven-up requires the Ras pathway for its function in photoreceptor determination. Development 121: 225-237.

Bier, E., L.Y. Jan, and Y.N. Jan. 1990. rhomboid, a gene required for dorsoventral Drosophila melanogaster. Genes \& Dev. 4: 190-203.

Brand, A.H. and N. Perrimon. 1993. Targeted gene expression as a means of altering cell fates and generating dominant phenotypes. Development 118: 401-415.

Campos-Ortega, J.A. and V. Hartenstein. 1997. The embryonic development of Drosophila melanogaster. Springer Verlag, N ew York, NY.

Clifford, R. and T. Schüpbach. 1989. Coordinately and differentially mutable activities of torpedo, the Drosophila melanogaster homolog of the vertebrate EGFR gene. Genetics 122: 771-787.

- - . 1992. The torpedo DER receptor tyrosine kinase is required at multiple times during Drosophila embryogenesis. Development 115: 853-872.

Edgar, B.A. and C.F. Lehner. 1996. Developmental control of cell cycle regulators: A fly's perspective. Science 274: 1646-1652.

Edgar, B.A. and P.H. O'Farrell. 1990. The three postblastodermal cel cycles of Drosophila embryogenesis are regulated in $\mathrm{G} 2$ by String. Cell 62: 469-480.

Edgar, B.A., D.A. Lehmann, and P.H. O'Farrell. 1994. Transcriptional regulation of string (cdc25): A link between developmental programming and the cell cycle. Development 120: 3131-3143.

Follette, P.J. and P.H. O'Farrell. 1997. Connecting cell behavior to patterning: Lessons from the cell cycle. Cell 88: 309-314.

Freeman, M. 1997. Cell determination strategies in the Drosophila eye. Development 124: 261-270.

Freeman, M., C.G. Klämbt, C.S. Goodman, and G.M. Rubin. 1992. The argos gene encodes a diffusable factor that regulates cell fate decisions in the Drosophila eye. Cell 69: 963-975.

Gabay, L., H. Scholz, M. Golembo, A. Klaes, B.-Z. Shilo, and C. Klämbt. 1996. EGF receptor signaling induces pointed P1 transcription and inactivates Yan protein in the Drosophila embryonic ventral ectoderm. Development 122: 3355-3362.

Gabay, L., R. Seger, and B.-Z. Shilo. 1997. In situ activation pattern of Drosophila EGFR pathway during development. Science 277: 11031106.

Greenwald, I. and G.M. Rubin. 1992. Making a difference: The role of cell-cell interactions in establishing separate identities for equival ent cells. Cell 68: 271-281.

Gurdon, J.B. 1992. The generation of diversity and pattern in animal devel opment. Cell 68: 185-199.

Hiromi, Y., M. Mlodzik, S.R. West, G.M. Rubin, and C.S. Goodman 1993. Ectopic expression of seven-up causes cell fate changes during ommatidial assembly. Development 118: 1123-1135.

Hoch, M., K. Broadie, H. Jäckle, and H. Skaer. 1994. Sequential fates in a single cell are establishd by the neurogenic cascade in the $M$ al pighian tubules of Drosophila. Development 120: 3439-3450.

Janning, W., A. Lutz, and D. Wissen. 1986. Clonal analysis of the blastoderm anlage of the $\mathrm{M}$ al pighian tubules in Drosophila melanogaster. Wilhelm Roux's Arch. Dev. Biol. 195: 22-32.

Karpen, G.H. and A.C. Spradling. 1992. Analysis of subtel omeric heterochromatin in the Drosophila minichromosome Dp1187 by single P element insertional mutagenesis. Genetics 132: 737-753.

Klämbt, C. 1993. The Drosophila gene pointed encodes two ETS-like proteins which are involved with the development of the midline glial cells. Development 117: 163-176.

Knoblich, J.A., K. Sauer, L. Jones, H. Richardson, R. Saint, and C.F. Lehner. 1994. Cyclin E controls S phase progression and its down-regulation during Drosophila embryogenesis is required for the arrest of cell proliferation. Cell 77: 107-120.

Kolodkin, A.L., A.T. Pickup, D.M. Lin, C.S. Goodman, and U. Banerjee. 1994. Characterization of Star and its interactions with sevenless and EGFR during photoreceptor cell development in Drosophila. Development 120: 1731-1745.

Kramer, S., S.R. West, and Y. Hiromi. 1995. Cell fate control in the Drosophila retina by the orphan receptor Seven-up: Its role in the decisions mediated by the ras signaling pathway. Development 121: 1361-1372.

Lawrence, P.A. and G. Struhl. 1996. M orphogenesis, compartments and pattern: Lessons from Drosophila? Cell 85: 951-961.
Mlodzik, M., Y. Hiromi, C.S. Goodman and G.M. Rubin. 1990. The Drosophila seven-up gene, a member of the steroid receptor gene superfamily, controls photoreceptor cell fates. Cell 60: 211-224.

N üsslein-Vol hard, C. 1991. Determination of the embryonic axes of Drosophila. Development (Suppl.) 1-10.

Power, R.F., J.P. Lydon, O.M. Conneely, and B.W. O'Malley. 1991. Dopamine activation of an orphan of the steroid receptor superfamily. Science 252: 1546-1548.

Richardson, H.E., L.V. OKeefe, S.I. Reed, and R. Saint. 1993. A Drosophila G1- specific cyclin E homolog exhibits different modes of expression during embryogenesis. Development 119: 673-690.

Schlessinger, J. and A. Ullrich. 1992. Growth factor signaling by receptor tyrosine kinases. Neuron 9: 383-391.

Schweitzer, R. and B.Z. Shilo. 1997. A thousand and one roles for the Drosophila EGF receptor. Trends Genet. 13: 191-196.

Skaer, H. 1989. Cell division in Mal pighian tubule development in Drosophila melanogaster is regulated by a single tip cell. Nature 342: 566-569.

- - . 1993. The alimentary canal. In The development of Drosophila melanogaster (ed. A. Martinez Arias, M. Bate), pp. 941-1012. Cold Spring Harbor Laboratory Press, Cold Spring Harbor, NY.

Thummel, C.S. 1995. From embryogenesis to metamorphosis: The regulation and function of Drosophila nucl ear receptor superfamily members. Cell 83: 871-877.

Tsai, S.Y. and M.J. Tsai. 1997. Chick oval bumin upstream promotortranscription factors (COUP-TFs): Coming of age. Endokr. Rev. 18: $229-240$

Wessing, A. and D. Eichel berg. 1978. Mal pighian tubules, rectal papillae and excretion. In The genetics and biology of Drosophila (ed. M. A shburner and T.R.F. Wright). A cademic Press, London, UK.

Xu, T. and G.M. Rubin. 1993. Analysis of genetic mosaics in developing and adult Drosophila tissues. Devel opment 117: 1223-1237.

Zak, N.B. and B.-Z. Shilo. 1992. Localization of DER and the pattern of cell divisions in wild type and Ellipse eye imaginal discs. Dev. Biol. 149: $448-456$

Zelhof, A.C., T. Yao, J.D. Chen, R.M. Evans, and M. McKeown. 1995. Seven-up inhibits ultraspiracle-based signaling pathways in vitro and in vivo. Mol. Cell. Biol. 15: 6736-6745. 


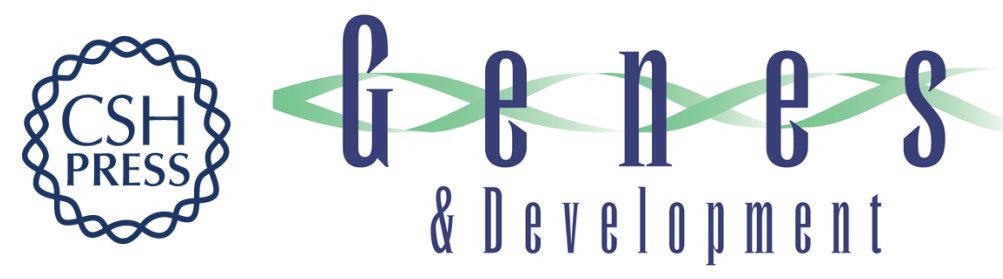

\section{Seven-up, the Drosophila homolog of the COUP-TF orphan receptors, controls cell proliferation in the insect kidney}

Birgit Kerber, Sonja Fellert and Michael Hoch

Genes Dev. 1998, 12:

Access the most recent version at doi:10.1101/gad.12.12.1781

References This article cites 35 articles, 19 of which can be accessed free at: http://genesdev.cshlp.org/content/12/12/1781.full.html\#ref-list-1

License

Email Alerting

Receive free email alerts when new articles cite this article - sign up in the box at the top Service right corner of the article or click here.

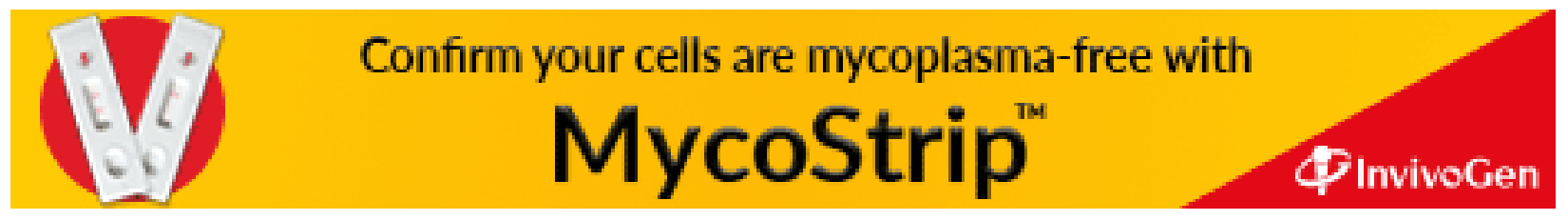

